\title{
Natalka Gold Deposit
}

\author{
E. M. Nikitenko, T. I. Mikhalitsyna, M. I. Fomina, 0. T. Sotskaya \\ North-East Interdisciplinary Scientific Research Institute N. A. N. A. Shilo, Far East Branch, Russian Academy of \\ Sciences (NEISRI FEB RAS), Magadan, Russia \\ Email: elena mih-na@mail.ru, mihalitsina@neisri.ru
}

Received April 2014

\begin{abstract}
Studies were taken of ore-bearing rocks, ores and gravity concentrates from Natalka gold deposit by a set of complex methods including mineralogical, petrographic and geochemical research, gravity concentration, and electronic microscopy. The major form of Au found is native: free gold is larger and dispersed, in the form of microinclusions. The obtained results are the basis for an effective technology to extract gold and sequence of profitable mining of Natalka deposit.
\end{abstract}

\section{Keywords}

Yana-Kolyma Fold System, Natalka Gold Deposit, Mineralogical and Petrographic Characteristics, Chemical Composition, Gravitational Concentrates

\section{Geological Position of the Natalka Gold Deposit}

The Natalka gold deposit is one of the largest in Russia. Subsurface ore mining had been conducted at the mine until May 30, 2004, and was stopped because of its non-efficiency.

The geological position of the Natalka deposit is determined by its association with the margin of the assumed pluton in the zone of the Ten'ka deep fracture and caused by the geodynamic situation of the collision stage of the Yana-Kolyma folded system development. The Yana-Kolyma folded system, included in the infrastructure of the Verkhoyansk-Chukotka folding, has the regional north-western orientation and is represented by the association of Permian, Triassic, and Lower Jurassic hemipelagic and pelagic terrigenic rocks interpreted as a complex of underwater debris cone containing underwater rockslide horizons.

Sedimentary rocks at some places have higher grades of the syngenetic carbonaceous substance.

The deposit area is attached to the south-eastern part of the Yana-Kolyma folding system and located in the south-western wing of the Main Ayan-Yuryakh Anticlinoirum. The main structural element of the anticlinorium is the Ten'ka Anticline; its part in the basins of the Kulu and Nelkoba rivers is distinguished as the Ten'ka Ore District and includes three ore clusters: the Degdekan (Tokichan and Degdekan deposits), the Omchak (Natalka, Omchak, and Pavlik deposits), and Pioneer (Rodionovskoye, Igumenovskoye, and Klin deposits). The geological structure of the area comprises terrigenic Permian and Triassic deposits forming the section of about $5-7 \mathrm{~km}$ in total thickness. Very few Late Cretaceous volcanic formations lie on Permian strata with angular and stratigraphic discordancies. Magmatic formations in the area are divided in three complexes: the Late Jurassic complexes of dykes with mostly medium composition and batolith-like granitoid intrusives (the Kolyma type) and the Cretaceous complex uniting rocks from gabbro to leucocratic 
granits (the Omsukchan and the Okhotsk types). Dislocations with breaks of continuity in the area are quite numerous, clearly manifested, and to a great extent determine the structural plane of the area.

Dominating are longitudinal dislocations, mostly of the north-western strike and relatively folded structure. The most important longitudinal fracture is considered the Omchak fracture, associated with the formation of all gold deposits of the Omchak Ore Cluster. In the northern part of the area, the large latituinal Inyakan-Kolyma fracture has been distinguished; it is of significance for the gold metallization formation and refers to the category of ore-concentrating open structures. At its intersection with the Omchak fracture, the Omchak dome-circular structure has been marked; here the Natalka gold deposits have been localized. The deposits refer to the type of vein-veinlet and stockwork zones. Metallogenically, they refer to the pyritearsenopyrite type of the gold-quartz less-sulfide formation.

The previous research of the essential ore composition mostly involved the deposit deep horizons (+600 $\mathrm{m}$ ) in underground works. However, with the start of open-pit works at surface sites (horizon $+940 \mathrm{~m}$ ), the research of essential ore composition and gold distribution in subsurface zones at the first batch of the deposit exploration come into the spotlight.

Within the current research framework, large-volume ore samples presenting most characteristic metallization types were taken and studied by a set of methods including mineralogical, petrographic, and geochemical research, gravity concentration, and electronic microscopy.

\section{Mineralogical and Petrographic Characteristics of the Ore-Bearing Rock at the Natalka Deposit}

Ore-bearing rocks are hydrothermally metamorphized sedimentary and igneous-sedimentary deposits of the Permian age (aleurolites, sandstones, gravelites with inclusions of the tuffaceous material) divided in the Pioneer $\left(\mathrm{P}_{1-2} \mathrm{Pn}\right)$, Atka $\left(\mathrm{P}_{3} \mathrm{at}\right)$, and Omchak $\left(\mathrm{P}_{3} \mathrm{Om}\right)$ suites (Byakov \& Vedernikov, 1990). The leading structural and morphological type of metallization is the vein-veinlet one. Ore bodies are zones of contiguous quartz veinlets with metasomatic silicification sites and rare lenses and veins of quartz. The sulfides in ores do not exceed $1-3$ vol.\%, seldom 5 vol.\%. 95\% - 99\% ore minerals are represented by arsenopyrite and pyrite. The deposit refers to the pyrite-arsenopyrite mineral type of the gold-quartz formation (Goncharov et al., 2002).

The Natalka deposit area is traditionally divided in 3 sites (North-Western, Central, and South-Eastern), which differ in their geological structure and location.

The Central site is attached to the south-western wing of the Natalka syncline and adjacent to its central lock part. Ore-bearing rocks are well sheeted and cleavage, with veinlets of the quartz-feldspar composition from less than $1 \mathrm{~mm}$ to $1 \mathrm{~cm}$ thick, seldom thicker. Veinlets form subparallel bundles and clusters of various orientation.

In the clastogenic part, debris of albits and fine-grained aggregate of the quartz-albite composition dominate. Albitization of potassium feldspars, limonite development (to 3\%), and the reduction of sericite in the cement with chlorite increase is observed. Exposed is the intensive development of carbonate as the dispersed impregnation on the basic rock matrix as well as of irregular grain aggregates filling the inter-grain space and replacing the debris. Ore mineralization $(0.01 \%-1.5 \%)$ is unevenly distributed. Among ore minerals, arsenopyrite, pyrite, chalcopyrite, pyrrotine, galena, sphalerite, marcasite, and native gold are identified. Two generations of arsenopyrite (short- and fine-prismatic) have been distinguished. The short-prismatic arsenopyrite is associated with the deposition of the main part of native gold. Gold grain sizes vary from 0.001 to $0.2 \mathrm{~mm}$.

The North-Western site of the deposit is attached to the north-western wing of the Natalka syncline, where rocks are mostly monoclinally bedded with a steep $\left(50^{\circ}-60^{\circ}\right)$ fall to the north-east. Rock is represented mostly by tuffaceousslates containing numerous interbeds of sandstones and fine-pebble conglomerates with quarts-feldspar veinlets developing. Ore zones have cross deposition related to the dominating stretch of ore-bearing rocks and deviate from it for $20^{\circ}-30^{\circ}$.

The South-Eastern site of the deposit is attached, respectively, to the southern part of the Natalka syncline; here bedrocks have flat tilty dip. At the site mostly clayey slates are developed. Concerning the mineral composition, rocks are distinguished with the reduced number of feldspars and the development of limonite (to 6\%). The number of ore mineralization on the two sites of the deposit decreases to $1 \%$; mineralization is unevenly distributed. The ore mineral composition is analogous to that at the Central site. The distinguishing characteristic is the absence of marcasite, sporadic ore occurrence (South-Eastern site), and the development of the oxidation zone (chalcosine, covellite, and scorodite). Native gold of $0.1-0.07 \mathrm{~cm}$ is deposited in quartz interstitions and 
interlocks with short-prismatic arsenopyrite.

\section{Chemical Composition of Ore-Bearing Rocks at the Natalka Deposit}

By the chemical composition all of the analyzed ore-bearing rock samples are found to be similar. The major components are earth silicon and aluminum, with the total average content of $78.02 \%$. The highest amount of earth silicon (75.71\%) is marked within the Central site. The average contenst of $\mathrm{SiO}_{2}$ by sites are: South-Eastern-63.66\%, Central-64.34 \%, North-Western-64.07\%. The amount of earth silicon distinguishes the original rocks as persilicic. There are also tributary components- $\mathrm{Fe}_{2} \mathrm{O}_{3}, \mathrm{FeO}, \mathrm{Na}_{2} \mathrm{O}, \mathrm{K}_{2} \mathrm{O}, \mathrm{CaO}, \mathrm{MgO}$; their total average content is $15.15 \%$, including alkali elements $\mathrm{Na}_{2} \mathrm{O}$ and $\mathrm{K}_{2} \mathrm{O}-5.88 \%$ avg. (3.69\% and 2.18\%, accordingly).

Cumulate alkalinity fluctuates from $4.97 \%$ to $6.75 \%$, which corresponds the higher alkalinity of the rock composition. In most samples of the base ore, $\mathrm{Na}_{2} \mathrm{O}$ is dominating over $\mathrm{K}_{2} \mathrm{O}$; however, at the flanks of the deposit, inside ore-bearing rocks, the $\mathrm{K}_{2} \mathrm{O}$ slightly exceeds the $\mathrm{Na}_{2} \mathrm{O}$ content, due to the increased amount of the hydromicaceous material in the rock composition. Maximum alkali content (5.37\%) is found in the Central site rocks. Average contents by sites are: South-Eastern- $\mathrm{Na}_{2} \mathrm{O}-3.49 \%, \mathrm{~K}_{2} \mathrm{O}-2.57 \%$; Central section- $\mathrm{Na}_{2} \mathrm{O}-$ $3.73 \%, \mathrm{~K}_{2} \mathrm{O}-2.25 \%$; North-West $-\mathrm{Na}_{2} \mathrm{O}-3.77 \%, \mathrm{~K}_{2} \mathrm{O}-2.25 \%$. In relation to the $\mathrm{FeO} / \mathrm{Fe}_{2} \mathrm{O}_{3}$ content, the samples show significant fluctuations from 0.17 to $4.18 \mathrm{wt}$. \%; most samples of the base ore are characterized by $\mathrm{FeO}$ avg. (2.61 wt. \%) dominating over $\mathrm{Fe}_{2} \mathrm{O}_{3}$ avg. (2.23 wt. \%), which suggests the reducing conditions of the rock formation

$\mathrm{Al}_{2} \mathrm{O}_{3}$ (8.85\% - 15.47\%), $\mathrm{K}_{2} \mathrm{O}(1.04 \%$ - 3.31\%), and $\mathrm{MgO}(1.00 \%$ - 2.20\%) variations reflect the changes in the percentile content of mica and chlorite in the ore sample. Fluctuations in the $\mathrm{Fe}_{2} \mathrm{O}_{3}(0.91 \%-4.89 \%)$ content are mostly triggered by the sulfides amount variability. The increased up to $4.47 \%) \mathrm{CaO}$ content reflects the presence of calcite and apatite. The high content of $\mathrm{Na}_{2} \mathrm{O}$ in the rock is representative for albitemetasomatites. The $\mathrm{P}_{2} \mathrm{O}_{5}$ content levels fluctuate from 0.09 to $0.23 \%$, which is related to a phosphate-containing mineral (apatite) presence.

While comparing absolute contents of rock-forming oxides, that reflect the base ore composition, a number of the most informative petrochemical modules were examined (Yudovich \& Ketris, 2000). For the modules calculation, the oxide weight contents (\%) were used, and the calculations were made in accordance to "Standard UK” (Yudovich \& Ketris, 2000).

One of the universal indicators, intended for quantitative estimation of two most important supergene processes (desalinisation and hydrolysis) is hydrolyzate module (HM) $-\left(\mathrm{TiO}_{2}+\mathrm{Al}_{2} \mathrm{O}_{3}+\mathrm{Fe}_{2} \mathrm{O}_{3}+\mathrm{FeO}+\mathrm{MnO}\right) / \mathrm{SiO}_{2}$. The HM value in most base ore samples was found to exceed 0,30 , which allows to attribute these formations to clay rocks and greywackes; the Central site samples showed HM level - 0.20 - 0.30 (avg. 24,6), appropriate for clay silicites (cherty-silica shales), polymictic quartz sandstones, and aleurolites; in a single ore sample HM level -0.17 , to be appropriate for low-shale volume silicites (silica-cherty shales), oligomictic quartz sandstones, and aleurolites $(\mathrm{HM}=0.10-0.20)$.

For a more detailed characteristic of hydrothermally converted rocks, additional petrochemical factors were used, which took into account ferruginosity, femicity, titanium, and alkalinity.

The ferrous module (FM)- $\left(\mathrm{FeO}+\mathrm{Fe}_{2} \mathrm{O}_{3}+\mathrm{MnO}\right) /\left(\mathrm{Al}_{2} \mathrm{O}_{3}+\mathrm{TiO}_{2}\right)$-reflects the correlation between ferrous and aluminous hydrolysis products. The FM value for most ore samples is significantly less than one and fits in the $0.30-0.39$ interval, which corresponds to normo-ferruginous siallites, with a standard content of basic petrogenic oxides. The $\mathrm{FM}$ module $\left(\left(\mathrm{FeO}+\mathrm{Fe}_{2} \mathrm{O}_{3}+\mathrm{MgO}\right) / \mathrm{SiO}_{2}\right)$ is very important for recognizing petro- and pyrogenic deposits—such rocks are almost always labeled with FM $<0.10$. On the scale of the femic FM module, ore samples fit the 0.06 - 0.13 interval, with an obvious attraction of micaseous-chloritic rock variations to its lower boundary. In greywackes and polymictic quartz sandstones, due to a content increase of iron and magnesium within the chlorate-carbonated cement, the interval of FM median values rises to $0.12-0.13$. Based on the normalized alkalinity value- $\left(\mathrm{Na}_{2} \mathrm{O}+\mathrm{K}_{2} \mathrm{O}\right) /\left(\mathrm{Al}_{2} \mathrm{O}_{3}\right)$, ore samples from the North-Western and South-Eastern sites do not exceed the $0.20-0.40$ limit, which usually corresponds a standard mixture of hydromicas and feldspars. However, in the rocks enriched in feldspar clastolites, this value significantly increases to $0.40-0.50$ and over 0.50 (Central site), which is explained by a sharp increase of sodium with in albite-oligoclase.

The data from the cluster analysis of basic petrogenic elements used, the following regularities have been exposed: three groups of components clearly distinguish themselves: 1) $\mathrm{Au}_{-} \mathrm{SiO}_{2}-\mathrm{Na}_{2} \mathrm{O}$, which emphasizes the quartz-feldspathic veinlet composition within the rock, with gold associated with them; 2) $\mathrm{TiO}_{2}-\mathrm{Al}_{2} \mathrm{O}_{3}-\mathrm{P}_{2} \mathrm{O}_{5}-$ $\mathrm{MnO}-\mathrm{K}_{2} \mathrm{O}$, which testifies to titanian, phosphate, and argillous minerals in the rock composition; 3) FeO-MgO- 
Ca, which reflects the iron-magnesium-calcic tenor of carbonates.

Statistical adaptation of the results of the ore-bearing rock atomic emission spectrum analysis allowed to establish the petrogenic nature of $\mathrm{Pb}, \mathrm{Cr}, \mathrm{As}, \mathrm{W}, \mathrm{Mo}$, Sn, Cu, Ag, Zn, Ni, Co, Au accumulation. The R-type cluster-analysis dendrogram shows four separate geochemical assemblages: 1) Cr-Mo-As; 2) Co-Zn; 3) W-Ag-Au; 4) $\mathrm{Cu}-\mathrm{Ni}-\mathrm{Pb}-\mathrm{Sn}$. The group-forming elements have a hybrid petrogenic specialization; the 3-rd group distinctly reflects the gold ore specialization. All geochemical microelement assemblages of hold positive interrelationship. When analyzing concentration distribution of the mineralization-indicating elements in relation to the geochemical background of the Natalka deposit (Goncharov et al., 2002), the following has been found: the SouthEastern site-As from 5 to 116 geophones, W-4, Ag-2, Au—1 geophone and lower; Central site-Au—-7 - 9 geophones, As to 128, W-5 - 6, Ag-2 geophones; North-Western-As from 11 to 68 geophones, W-3 - 5, Ag-1 - 3, Au - content varies from 1 to 7 geophones.

\section{Technological Middling Research Results}

Concentrates were prepared from $3 \mathrm{~kg}$ of ore charge by gravity concentration, using centrifugal vibratory concentrator (CVC-100-2M); they were “mounted” into the epoxide blocks and polished. Quantitative evaluation of the concentrated product material composition was performed on the FEI QEMSCAN hardware and softwarebased on Carl Zeiss SEM EVO-50.

The QEMSCAN automated system expedites obtaining quantitative mineralogical properties: relative mineral content in a sample, mineral associations, grain size, and mineral grain-opening degree. The research was conducted in the particle mineral analysis (PMA) mode, displaying separate mineral particles, as well as in the trace mineral search (TMS) mode, displaying only the particles that contain specific required stages. The measurement conditions were as follows: accelerating applied voltage $5 \mathrm{kV}$, electrical current in the Faraday cup $5 \mathrm{nA}$. For the separate particles composition research, the QUANTAX (Bruker) quantitative analysis system was used, included in the QEMSCAN complex.

The total of three centrifugal concentrated samples was examined. Samples № 1 and № 2 characterize the veinlet-impregnated ore that contains $\sim 1-3 \%$ sulfides extracted from the Central section of the deposit at the depth of 12 - 15 meters. Sample № 3 characterizes the impregnated ore containing 3\% sulfides extracted from the South-Eastern section at a depth of 250 meters, in a $11(122.6-125.6 \mathrm{M})$ cross cut.

The quantitative mineralogical analysis results of the gravitational concentrates show that the concentrates vary in composition as well as in the sulfide amount (Table 1).

Arsenopyrite is the major ore mineral; pyrite has subordinate spreading. Other sulfides do not exceed 1\%, except galena in Concentrate 1 . The same concentrate contains big amounts ( 31\%) of slime-forming materials, which can negatively affect the gold recovery during the following cyanidation. With particles smaller than 0.1 $\mathrm{mm}$, up to $40 \%$ of gold occur in loose (open) condition; the rest, in the form of attachments or inclusions, is associated with other minerals. Approximately $10.5 \%$ of gold is associated with arsenopyrite and pyrite; no more than $2 \%$, with galena; approximately $3 \%$, with quartz; and 3.5\%, with rock-forming minerals. The content of the isomorphic silver impurity in gold fluctuates from 16 to $19 \%$. Gold microinclusions in sulfides are quantitatively subordinate.

The gravity concentrates contain free native gold, closely associated with sulfides. In Concentrate 1, the gold grade is $\sim 7 \%$ (see Table 1), mostly in a loose condition, in relatively large grains; microinclusions in sulfides are quantitatively subordinate. The loose gold particles are irregularly shaped, reaching to $200 \mu \mathrm{m}$ in size.

Dispersed micrograins of gold occur as oval and pseudoisometric microinclusions in arsenopyrite; less often, in arsenical pyrite. Loose gold fills sulfide microfractures and defects; gold grains vary from 0.3 to $15 \mu \mathrm{m}$ in size; gold fineness fluctuates from 820 to $850 \%$.

For the first time in the Natalka ores, telluric silver (hessite) has been found. Hessite has been discovered in the gravity concentrate obtained from the vein-disseminated ore from the Central site. Grains vary from 2 to 5 $\mu \mathrm{m}$ in size, their shape is oval and isometric. The hessite content is close to theoretical.

Concentrate 1, which comes from the Central site ore, shows $0.65 \%$ presence of cobaltite isometric grains, 20 to $35 \mu \mathrm{m}$ in size. Cobaltite is closely associated with galena, as cobaltite grains almost constantly contain 0.5 to 10 - $15 \mu \mathrm{m}$ galena inclusions. Cobaltite itself constantly contains 2\% - 5\% nickel (Ni) and 3\% - 5\% iron (Fe) impurities. 
Table 1. The mineral composition of the gravitational concentrates.

\begin{tabular}{|c|c|c|c|}
\hline \multirow{2}{*}{ Mineral } & \multicolumn{3}{|c|}{ The mineral composition of the gravitational } \\
\hline & Concentrate №1 & Concentrate №2 & Concentrate №3 \\
\hline Gold/Electrum & 6.86 & 0.90 & 0.23 \\
\hline Arsenopyrite & 24.65 & 75.38 & 92.49 \\
\hline Pyrite & 5.17 & 9.45 & 2.09 \\
\hline Galena & 2.41 & 0.18 & 0.06 \\
\hline Cobaltite & 0.65 & - & - \\
\hline Sphalerite & - & 0.10 & 0.08 \\
\hline Chalcopyrite & - & 0.14 & 0.06 \\
\hline Limonite & 0.55 & 0.15 & 0.17 \\
\hline Goethite & - & 0.04 & 0.08 \\
\hline Magnetite & - & - & 0.04 \\
\hline Monazite & 0.15 & 0.05 & - \\
\hline Garnet & 0.22 & 0.09 & - \\
\hline Rutile/Anatase & 2.95 & 0.59 & 0.31 \\
\hline Zircon & 0.57 & - & - \\
\hline Baryte & 0.46 & 0.08 & 0.05 \\
\hline Apatite & 0.72 & 0.05 & 0.05 \\
\hline Biotite & 3.58 & 0.39 & 0.29 \\
\hline Muscovite & 3.07 & 0.59 & - \\
\hline Calcite & 3.37 & 0.07 & - \\
\hline Pyroxene & 0.68 & - & - \\
\hline Amphibole & 0.50 & 0.22 & - \\
\hline Albite & 9.88 & 2.36 & 0.29 \\
\hline K-feldspar & 8.39 & 1.84 & - \\
\hline Quartz & 17.13 & 2.25 & 0.23 \\
\hline Others & 8.05 & 5.09 & 3.48 \\
\hline Total & 100.00 & 100.00 & 100.00 \\
\hline
\end{tabular}

\section{Findings}

The richest in useful components ( $\mathrm{Au}, \mathrm{Ag}$ ) ore-containing rocks at the Central site are characterized by maximal $\mathrm{Na}_{2} \mathrm{O}$ and $\mathrm{SiO}_{2}$ content. The feasible exploration sequence for the Natalka deposite consists of the following stages: first, the Central site, then the North-Western, and finally, the South-Eastern site.

The revealed features of the mineral-petrographic composition show that the effective gold extraction from the Central site ore is possible through gravity concentration in a series of stages and the consequential extraction of magnetics based on the size class. Working the South-Eastern site ore, it is essential to consider the presence of the oxidation zone minerals, including high contents of limonite; therefore, on the flotation concentration stage it is important to select the right floatation reagents. To avoid overgrinding of the soft clay slates from the South-Eastern site ores, as well as of heavily sheeted Central site ores, especially while working the upper levels, grinding mill operating conditions should be closely monitored.

A new data on different mineral compositions of the concentrate samples, various gold associations with other minerals in them, and different degrees of the gold grain exposure has been obtained.

The major form of Au found is native: free gold is larger and dispersed, in the form of microinclusions. The main minerals, containing dispersed microscopic gold microinclusions, are arsenopyrite and arsenical pyrite.

A new exploration form of silver (telluride, or hessite) has been exposed; also, relatively wide cobaltite distribution of has been demonstrated.

\section{References}

Byakov, A. S., \& Vedernikov, I. L. (1990). The Permian Deposits Stratigraphy in the North-Eastern Rim of the Okhotsk 
massif, the Central and South-Eastern Parts of the Ayan-Yuryakh Anticlinorium. Preprint. Magadan: NEISRI FEB AS USSR, 69 p.

Goncharov, V. I., Voroshin, S. V., \& Sidorov, V. A. (2002). Natalka Gold Ore Deposit. Magadan: NESC FEB RAS, 250 p. Yudovich, Y. E., \& Ketris, M. P. (2000). Basics of Lithochemistry. Saint-Petersburg: Science, 479 p. 